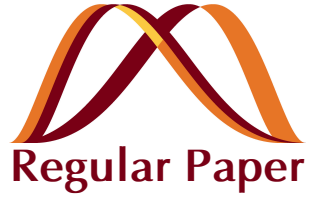

\section{Effect of an Electric Field on the AC Electrical Treeing in Various Epoxy/Reactive Diluent Systems}

\author{
Jeong- Hwan Bang \\ Department of Environmental Health, Seonam University, Namwon 590-711, Korea \\ Jae-Jun Park \\ Department of Electrical and Electronic Engineering, Joongbu University, Geumsan 312-702, Korea
}

Received August 23, 2013; Revised August 28, 2013; Accepted October 16, 2013

\begin{abstract}
The effect of an electric field on the ac electrical treeing in various epoxy/reactive diluent systems was studied in a needle-plate electrode geometry. Diglycidyl ether of bisphenol A (DGEBA) type epoxy was used as a base resin, and 1,4-butanediol diglycidyl ether (BDGE) or polyglycol (PG) as a reactive diluent was introduced to the DGEBA system, in order to decrease the viscosity of the DGEBA epoxy system. BDGE was acted as a chain extender, and PG acted as a flexibilizer, after the curing reaction. To measure the treeing initiation time and the propagation rate, three constant alternating currents (ac) of 10, 13 and $15 \mathrm{kV} / 4.2 \mathrm{~mm}(60 \mathrm{~Hz})$ were applied to the specimen, in a needle-plate electrode arrangement, at $30^{\circ} \mathrm{C}$ of insulating oil bath. When $10 \mathrm{kV} / 4.2 \mathrm{~mm}(60 \mathrm{~Hz})$ was applied, the treeing initiation time and the propagation rate in the DGEBA system were $356 \mathrm{~min}$ and $1.10 \times 10^{-3} \mathrm{~mm} / \mathrm{min}$, respectively, those in the DGEBA/ BDGE system were $150 \mathrm{~min}$ and $1.14 \times 10^{-3} \mathrm{~mm} / \mathrm{min}$, respectively. Those in the DGEBA/PG system were $469 \mathrm{~min}$ and $1.05 \times 10^{-3} \mathrm{~mm} / \mathrm{min}$, respectively. As $15 \mathrm{kV} / 4.2 \mathrm{~mm}(60 \mathrm{~Hz})$ was applied, the propagation rate in the DGEBA system was $5.41 \times 10^{-3} \mathrm{~mm} / \mathrm{min}$, and that in the DGEBA/PG system was $1.42 \times 10^{-3} \mathrm{~mm} / \mathrm{min}$. These values meant that PG could be used as a reactive diluent in the DGEBA system, without the deterioration of the insulation breakdown property.
\end{abstract}

Keywords: Electrical treeing, Epoxy, Reactive diluent, Propagation rate

\section{INTRODUCTION}

Epoxy resins have good mechanical and thermal properties, as well as excellent electrical properties; thus they have been used as insulation materials in the field of heavy electric equipment, such as mold-type transformers, current transformers (CT), potential transformers (PT), metering out-fit (MOF), gas switching gears, and so on [1-3]. In order to achieve these performances, many kinds of inorganic fillers, such as silica $\left(\mathrm{SiO}_{2}\right)$ [4], alumina $\left(\mathrm{Al}_{2} \mathrm{O}_{3}\right)$ [5], mica [6], aluminum nitride (AlN) [7], titanium dioxide $\left(\mathrm{TiO}_{2}\right)$ [8], etc. have been incorporated into the epoxy resins.

However, when inorganic filler was incorporated into an ep-

${ }^{\dagger}$ Author to whom all correspondence should be addressed: E-mail: jjpark@joongbu.ac.kr

Copyright $\odot 2013$ KIEEME. All rights reserved.

This is an open-access article distributed under the terms of the Creative Commons Attribution Non-Commercial
License (http://creativecommons.org/licenses/by-nc/3.0) which permits unrestricted noncommercial use Listribution, and reproduction in any medium, provided the original work is properly cited
dister oxy resin, the viscosity became too high. So it was very difficult, not only to disperse the fillers homogeneously, and to remove bubbles from the epoxy/filler mixture, but also to inject the viscous mixture into a mold, during the curing process. Therefore, in order to decrease the viscosity, plasticizers, organic solvents or reactive diluents were introduced to the epoxy/filler composites, so that bubbles were easily removed from the composites, after injection into a mold.

However, the plasticizers disturbed the cure reaction of the epoxy system, so that the crosslink density decreased. This caused decrease of the electrical, mechanical and thermal properties of the epoxy system. And, when organic solvent was used, it should be removed completely after mixing the epoxy, fillers and organic solvent. If not, it might act as an impurity, so that the electrical, mechanical and thermal properties of the epoxy composite would be negatively affected. Reactive diluents were used, in order to decrease the viscosity during mixing, and the electrical treeing phenomenon was studied, in order to estimate 
the insulation characteristics of neat epoxies or their nanocomposites, because the treeing phenomenon was often referred to as the most important mechanism for the deterioration of polymeric insulators (e.g. high voltage polymeric cables) [9-12]. The treeing growth mechanism was divided into three processes: (1) incubation process, (2) initiation process, and (3) propagation process. If an electrical treeing was initiated, it would be propagated rapidly, and finally the breakdown would occur. Hence, the initiation time should be delayed, and the propagation rate be retarded, in order to get excellent insulation polymeric materials.

In my previous work [13], the effects of ambient temperature on the electrical treeing phenomenon were studied in needleplate electrodes, and in this study, three epoxy/reactive diluent systems for the insulation materials of heavy electric equipment were prepared, and the effects of electric field on the electrical treeing phenomenon were studied in needle-plate electrodes.

\section{EXPERIMENTS}

\subsection{Materials}

A commercial DGEBA (diglycidyl ether of bisphenol A) type epoxy resin, trade name YD 128 (Kukdo Chem. Co.), was used. The equivalent weight was $184 \sim 190$, and the viscosity was $11,500 \sim 13,500 \mathrm{cps}$ at $25^{\circ} \mathrm{C}$. The curing agent was Me-THPA (3or 4-methyl-1,2,3,6-tetrahydrophthalic anhydride), whose grade name was $\mathrm{HN}-2200$ (Hitachi Chem. Co.). It is widely used in the field of electric insulation. An accelerator was BDMA (benzyl-dimethyl amine, Kukdo Chem. Co.). A reactive diluent employed as a flexibilizer was a polyglycol (PG), under the trade name DY-040 (Ciba-Geigy Co.). Its molecular weight was about 7,000 10,000, and its viscosity was $60 \sim 90 \mathrm{cps}$ at $25^{\circ} \mathrm{C}$. Another reactive diluent as an aliphatic epoxy resin was purchased from Kukdo Chem. Co., under the trade name BDGE. Its equivalent weight was $120 \sim 140$, and its viscosity was $15 \sim 30 \mathrm{cps}$ at $25^{\circ} \mathrm{C}$.

\subsection{Specimen preparation for ac treeing test}

DGEBA (100 g), THPA (92 g) and reactive diluent (10 g) were well-mixed with a high-speed agitator at 5,000 rpm for $10 \mathrm{~min}$, and BDMA ( $1 \mathrm{~g}$ ) was mixed with the agitator for $3 \mathrm{~min}$. The mixture was poured into a mold having a cavity of $15 \times 15 \mathrm{~mm}^{2}$ with $30 \mathrm{~mm}$ height, in which a needle electrode was arranged beforehand, to make the distance of needle-plate electrodes be $4.2 \mathrm{~mm}$. Then it was cured at $120^{\circ} \mathrm{C}$ for $2 \mathrm{hr}$, post-cured at $150^{\circ} \mathrm{C}$ for $2 \mathrm{hr}$, and cooled slowly at a rate of $-0.5^{\circ} \mathrm{C} / \mathrm{min}$ until room temperature, to avoid internal stress. Finally, the opposite-side of the needle electrode in the epoxy specimen was coated with conductive silver paste.

\subsection{AC treeing test}

To measure the treeing initiation and propagation rate, three constant alternating currents (ac) of 10, 13, and $15 \mathrm{kV} / 4.2 \mathrm{~mm}$ $(60 \mathrm{~Hz})$ were applied to the specimen, in needle-plate electrode arrangement, in insulating oil bath at $30^{\circ} \mathrm{C}$. Then, the specimen was inserted into the insulating oil, and maintained sufficiently for $2 \mathrm{hr}$, until the temperature of the needle tip area reached to $30^{\circ} \mathrm{C}$. Then, high voltage (HV) was applied, by using an ac Endurance Voltage Tester (Haefely, Germany) at a rising speed of $1 \mathrm{kV} /$ s until $10 \mathrm{kV}$, and the test voltage was kept, until electrical breakdown took place. The treeing morphology was monitored by a video microscope system (ICS-305B, SOMETECH Inc.), and the treeing images were collected every $1 \mathrm{~min}$.

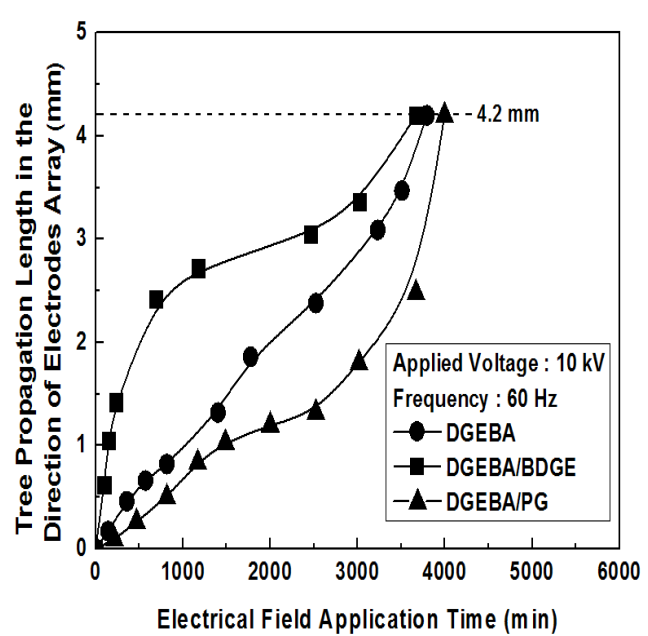

Fig. 1. Treeing growth rate in the various epoxy systems, tested in a constant electric field of $10 \mathrm{kV} / 4.2 \mathrm{~mm}(60 \mathrm{~Hz})$ at $30^{\circ} \mathrm{C}$.

\section{RESULTS AND DISCUSSION}

Figure 1 shows the treeing growth rate in DGEBA epoxy systems with BDGE or PG, tested under a constant electric field of $10 \mathrm{kV} / 4.2 \mathrm{~mm}(60 \mathrm{~Hz})$ at $30^{\circ} \mathrm{C}$. In the DGEBA system, electrical treeing was initiated in $356 \mathrm{~min}$, and propagated at the breakdown speed of $1.10 \times 10^{-3} \mathrm{~mm} / \mathrm{min}$, and finally, breakdown took place in 3,794 min. In the DGEBA/BDGE system, the treeing initiation time in needle-plate electrode geometry was $150 \mathrm{~min}$, which was 2.4 times lower, and the breakdown time was 3,669 min, which was 0.96 times lower, than that of the DGEBA system. The propagation rate of the DGEBA system was $1.10 \times 10^{-3} \mathrm{~mm}$ / min, and that in the DGEBA/BDGE system was $1.14 \times 10^{-3} \mathrm{~mm} /$ min, which was slightly faster. In the DGEBA/PG system, the treeing initiation time was $469 \mathrm{~min}$, the breakdown time was $3,996 \mathrm{~min}$, and the propagation rate was $1.05 \times 10^{-3} \mathrm{~mm} / \mathrm{min}$. The breakdown speed of the DGEBA/PG system was $5 \%$ slower than that of the DGEBA system.

The morphology of electrical treeing for the DGEBA/PG system was shown in Fig. 2. Typical behavior of the branch type electrical treeing was obtained from the morphology observation. That is to say, when a constant ac electric field of $10 \mathrm{kV} / 4.2$ $\mathrm{mm}(60 \mathrm{~Hz})$ was applied, electrons were injected and extracted at the needle tip, so that small electrical treeing was faintly initiated from the needle tip (Figure 2(a)). And then, electrons were injected and extracted at the newly generated conductive treeing tip, which had been carbonized, so that several branches newly appeared, and they grew rapidly, became fatter and darker, with many new branches (Figs. 2(b) 2(e)); and finally, the penetration breakdown took place, from the needle tip to the silver electrode plate (Fig. 2(f)).

To compare the effect of the diluents on the treeing phenomena, the treeing morphologies in the initiation stage and the propagation state in similar time are shown in Fig. 3. In the initial stage, many more branches were observed in the DGEBA/ BDGE system (Fig. 3(c)), than in the DGEBA system, and far fewer branches in the DGEBA/PG system are shown in Fig. 3(e). In the similar time of the propagation state, the primary branches formed many new secondary branches. That is to say, electrons injected and extracted at the needle tip initiated small electrical treeing from the needle tip, and then electrons were injected and extracted at the newly generated primary treeing tip, which had been carbonized, so that many branches newly appeared (Figs. $3(b, d, f)$ ), regardless of the diluents species. They grew, and be- 


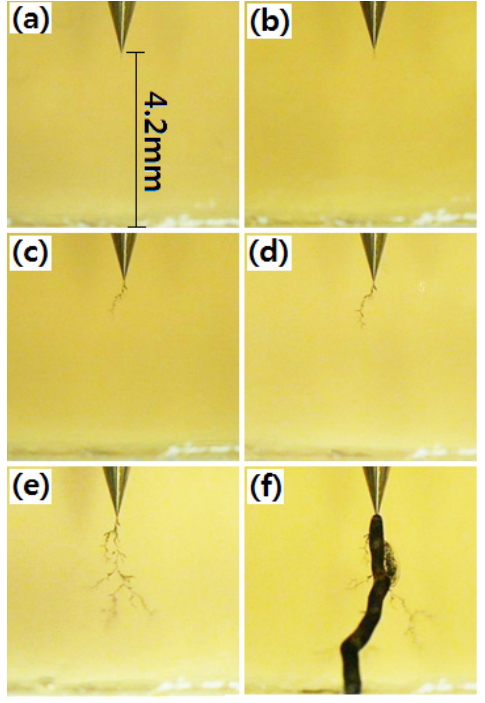

Fig. 2. Electrical treeing morphology of the DGEBA/PG system, tested in a constant electric field of $10 \mathrm{kV} / 4.2 \mathrm{~mm}(60 \mathrm{~Hz})$ at $30^{\circ} \mathrm{C}$, for (a) 180 min, (b) $300 \mathrm{~min}$, (c) 1,050 min, (d) 1,650 min, (e) 3,650 min, and (f) 3,996 min.

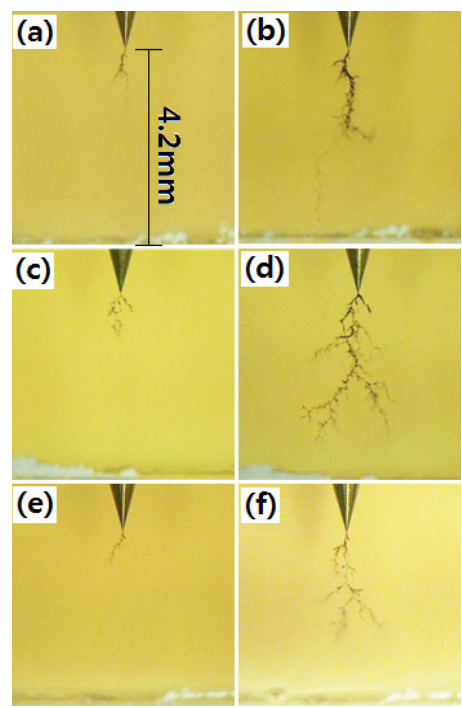

Fig. 3. Electrical treeing morphology of the various epoxy systems, tested in the constant electric field of $10 \mathrm{kV} / 4.2 \mathrm{~mm}(60 \mathrm{~Hz})$ at $30^{\circ} \mathrm{C}$, for (a) $420 \mathrm{~min}$, and (b) 3,550 min, in the DGEBA system, (c) $115 \mathrm{~min}$, and (d) 3,650 min, in the DGEBA/BDGE system, and (e) 1,050 min, and (f) 3,650 min, in the DGEBA/PG system.

came fatter and darker with new branches, and finally, the penetration breakdown took place.

Many more branches were shown in the DGEBA/BDGE system, as shown in Fig. 3(d), and far fewer branches were displayed in the DGEBA/PG system. These results meant that PG could be used as a reactive diluent in the DGEBA system, without the deterioration of the insulation breakdown property.

Figs. 4 and 5 show the treeing growth rate in the three epoxy systems tested in the electric field of $13 \mathrm{kV} / 4.2 \mathrm{~mm}$ and $15 \mathrm{kV} / 4.2$ $\mathrm{mm}$ at $30^{\circ} \mathrm{C}$, respectively. In the DGEBA system at $13 \mathrm{kV} / 4.2 \mathrm{~mm}$, the treeing propagation rate was $2.62 \times 10^{-3} \mathrm{~mm} / \mathrm{min}$, and that at $15 \mathrm{kV} / 4.2 \mathrm{~mm}$ was $5.41 \times 10^{-3} \mathrm{~mm} / \mathrm{min}$, which was far faster than the value $1.10 \times 10^{-3} \mathrm{~mm} / \mathrm{min}$ at $10 \mathrm{kV} / 4.2 \mathrm{~mm}$, as was ex-

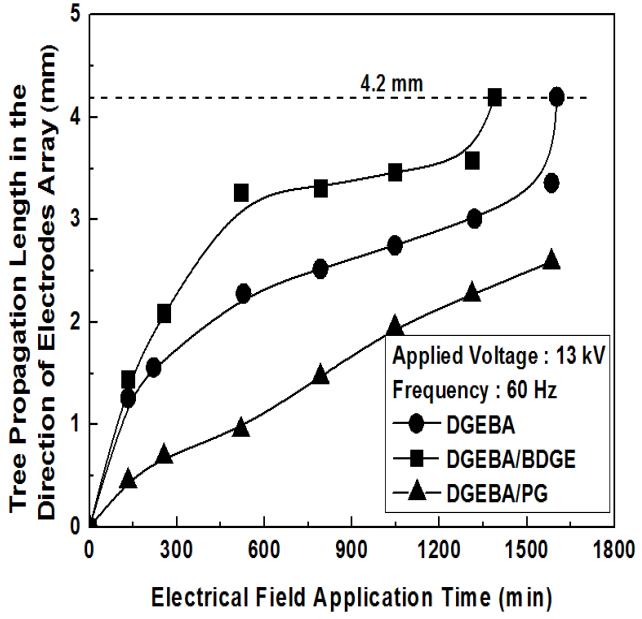

Fig. 4. Treeing growth rate in the various epoxy systems, tested in a constant electric field of $13 \mathrm{kV} / 4.2 \mathrm{~mm}(60 \mathrm{~Hz})$ at $30^{\circ} \mathrm{C}$.

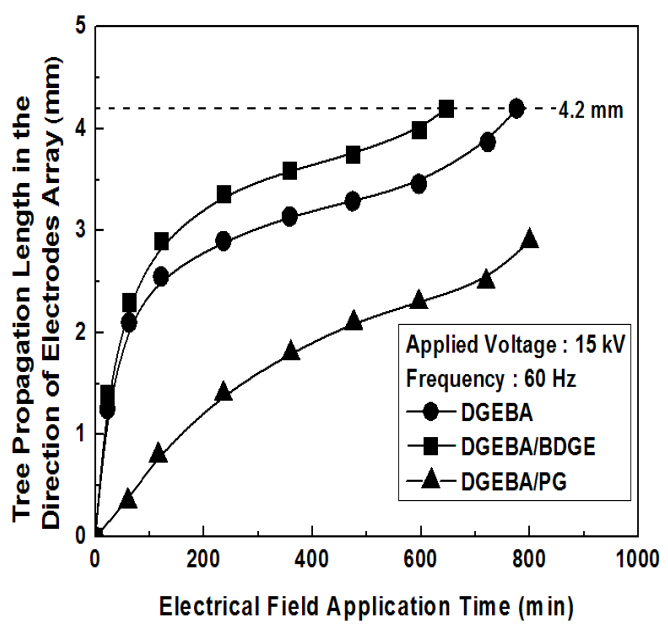

Fig. 5. Treeing growth rate in the various epoxy systems, tested in the constant electric field of $15 \mathrm{kV} / 4.2 \mathrm{~mm}(60 \mathrm{~Hz})$ at $30^{\circ} \mathrm{C}$.

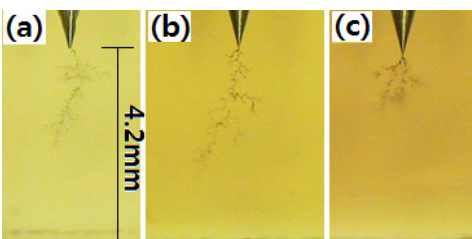

Fig. 6. Electrical treeing morphology of the DGEBA system, tested in (a) $10 \mathrm{kV} / 4.2 \mathrm{~mm}$ (3,550 min), (b) $13 \mathrm{kV} / 4.2 \mathrm{~mm}$ (720 min), and (c) $15 \mathrm{kV} / 4.2 \mathrm{~mm}$ (720 min). All were tested at $30^{\circ} \mathrm{C}$, in the electrical frequency of $60 \mathrm{~Hz}$.

pected. In the DGEBA/PG system at $13 \mathrm{kV} / 4.2 \mathrm{~mm}$, the treeing propagation rate was $1.63 \times 10^{-3} \mathrm{~mm} / \mathrm{min}$, and that at $15 \mathrm{kV} / 4.2$ $\mathrm{mm}$ was $3.62 \times 10^{-3} \mathrm{~mm} / \mathrm{min}$, which was far faster than the value $1.05 \times 10^{-3} \mathrm{~mm} / \mathrm{min}$ at $10 \mathrm{kV} / 4.2 \mathrm{~mm}$. These meant that the tree propagation rate increased with increasing electric field, as was expected.

To study the effect of the applied electric field on the treeing morphology, the electric treeing morphology of the DGEBA system in Fig. 6 was obtained after testing in (a) $10 \mathrm{kV} / 4.2 \mathrm{~mm}$ 


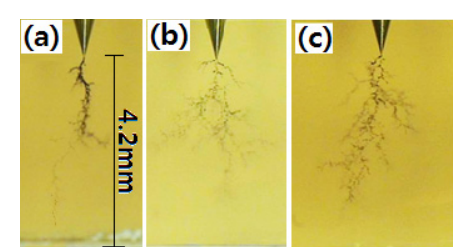

Fig. 7. Electrical treeing morphology of the (a) DGEBA, (b) DGEBA/ BDGE, and (c) DGEBA/PG systems, tested in $15 \mathrm{kV} / 4.2 \mathrm{~mm}(60 \mathrm{~Hz})$ at $30^{\circ} \mathrm{C}$ for $720 \mathrm{~min}$.

(3,550 min), (b) $13 \mathrm{kV} / 4.2 \mathrm{~mm}$ (720 min), and (c) $15 \mathrm{kV} / 4.2 \mathrm{~mm}$ (720 min). Typical branch type treeing was observed, regardless of the electric field. More precisely speaking, as the electric field increased, many more branches were formed. Compared to Fig. 3 , many more branches at the higher electric field were also observed in the other epoxy systems, as shown in Fig. 7. Far shorter treeing propagation was displayed in the DGEBA/PG system, and it meant that PG could retard the treeing propagation. Therefore, PG could be used as a reactive diluent in the DGEBA system, without the deterioration of the insulation breakdown property.

\section{CONCLUSIONS}

The effects of an electric field on the ac electrical treeing in DGEBA, DGEBA/BDGE and DGEBA/PG systems were studied, by carrying out the treeing test at constant alternating currents (ac) of 10,13 and $15 \mathrm{kV} / 4.2 \mathrm{~mm}(60 \mathrm{~Hz})$, in needle-plate electrode geometry. When $10 \mathrm{kV} / 4.2 \mathrm{~mm}(60 \mathrm{~Hz})$ was applied, the treeing initiation time and the propagation rate in the DGEBA system were $356 \mathrm{~min}$ and $1.10 \times 10^{-3} \mathrm{~mm} / \mathrm{min}$, respectively, and those in the DGEBA/BDGE system were $150 \mathrm{~min}$ and $1.14 \times 10^{-3} \mathrm{~mm} / \mathrm{min}$, respectively. Those in the DGEBA/PG system were $469 \mathrm{~min}$ and $1.05 \times 10^{-3} \mathrm{~mm} / \mathrm{min}$, respectively. When $15 \mathrm{kV} / 4.2 \mathrm{~mm}(60 \mathrm{~Hz})$ was applied, the propagation rate in the DGEBA system was 5.41 $\times 10^{-3} \mathrm{~mm} / \mathrm{min}$, and that in the DGEBA/PG system was $1.42 \times 10^{-3}$ $\mathrm{mm} / \mathrm{min}$. These values meant that PG could retard the treeing propagation; therefore, PG could be used as a reactive diluent in the DGEBA system, without the deterioration of the insulation breakdown property.

\section{ACKNOWLEDGMENT}

This work was supported by Joongbu University (2013).

\section{REFERENCES}

[1] J. Y. Lee, M. J. Shim and S. W. Kim, Polym. Eng. Sci., 39, 1993 (1999) [DOI: http://dx.doi.org/10.1002/pen.11592].

[2] Y. S. Cho, M. J. Shim and S. W. Kim, Mater. Chem. Phys., 66, 70 (2000) [DOI: http://dx.doi.org/10.1016/S0254-0584(00)002728].

[3] R. Sarathi, R. K. Sahu and P. Rajeshkumar, Mater. Sci. Eng.: A, 445, 567 (2007) [DOI: http://dx.doi.org/10.1016/ j.msea.2006.09.077].

[4] P. O. Henk, T. W. Kortsen and T. Kvarts, High Perform. Polym., 11, 281 (1999) [DOI: http://dx.doi.org/10.1088/09540083/11/3/304].

[5] M. Ehsani, Z. Farhadinejad, S. Moemen-bellah, S. M. Bagher alavi, M. M. S. Shrazi and H. Borsi, $26^{\text {th }}$ Internal Power System Conference, Tehran, Iran, 11-E-CAM-2359 (2011).

[6] P. Bajaj, N. K. Jha and A. Kumar, J. Appl. Polym. Sci., 56, 1339 (1995) [DOI: http://dx.doi.org/10.1002/app.1995.070561015].

[7] Y. Xu, D. D. L. Chung and C. Mroz, Composites: Part A, 32, 1749 (2001) [DOI: http://dx.doi.org/10.1016/S1359835X(01)00023-9].

[8] A. A. Wazzan, H. A. Al-Turaif and A. F. Abdelkader, PolymerPlastics Technology and Engineering, 45, 1155 (2006) [DOI: $10.1080 / 03602550600887285]$.

[9] T. Tanaka, G. C. Montanari and R. Mülhaupt, IEEE Trans. Dielectr. Electr. Insul., 11, 763 (2004) [DOI: http://dx.doi. org/10.1109/ TDEI.2004.1349782].

[10] T. Imai, F. Sawa, T. Ozaki, T. Shimizu, R. Kido, M. Kozako and T. Tanaka, Intern. Sympos. Electr. Insulating Materials, Kitakyushu, Japan, pp. 239 (2005).

[11] J. J. Park and J. Y. Lee, IEEE Trans. Dielectr. Electr. Insul. 17, 1516 (2010) [DOI: http://dx.doi.org/10.1109/TDEI.2010.5595553].

[12] D. J. Suh and O. O. Park, J. Appl. Polym. Sci., 83, 2143 (2002) [DOI: http://dx.doi.org/10.1002/app.10166].

[13] J. J. Park, Trans. Electr. Electron. Mater., 14, 221 (2013) [DOI: http://dx.doi.org/10.4313/TEEM.2013.14.4.221]. 